\title{
Preview: 2017 Materials Research Society Spring Meeting \& Exhibit
}

\author{
Phoenix Convention Center, Phoenix, Arizona | Meeting: April 17-21 | Exhibit: April 18-19 \\ www.mrs.org/spring2017
}

$F^{\circ}$ ollowing the successful relocation of the Materials Research Society (MRS) Spring Meeting to Phoenix, Ariz., last year, the 2017 MRS Spring Meeting will continue to be held at the Phoenix Convention Center, April 17-21. The scientific sessions will include many new and developing areas of materials research, as well as some well-established and popular topics. To complement the scientific sessions, tutorials will provide detailed introductions to particularly exciting areas of research, while the exhibit will showcase products of interest to the materials community.

Making up the core of the Meeting are five topical clusters of the technical program, encompassing 53 symposia. They are grouped into the following clusters:

Characterization, Theory and Modeling: This cluster of seven symposia serves to strengthen synergy between materials simulation and experiment for the purpose of accelerating the discovery and development of new materials for novel applications. Special focus will be on advanced algorithms for materials simulation across length scales, as well as in situ electron microscopy and nanomechanical characterization of dynamic and mechanically coupled phenomena.

Electronic Devices and Materials: This cluster of 14 symposia aims to push forward application-driven materials research, focusing on a wide range of materials systems for electronic, photonic, and optoelectronic devices. It includes materials for quantum technologies, photovoltaics and upconversion, plasmonics, metamaterials, and future highly integrated optoelectronic circuits, as well as for the interface with neurobiology.

Energy Storage and Conversion: There are more than a dozen symposia in this cluster, including solar fuels, photovoltaics (perovskite, chalcogenide, concentrated, multi-junction), nuclear materials, caloric materials, energy storage (batteries, fuel cells, thermoelectrics, electrodes, interfaces, mechanics, multivalent), spintronics, piezotronics, magnetoelectrics, nanogenerators, and soft magnets for power electronics.
Nanomaterials: The nanomaterials cluster features 10 symposia dedicated to a wide range of materials and applications: 1D nanowires, 2D materials, composites, as well as materials aimed at particular applications such as catalysis, energy, and functioning in extreme environments. Many of the symposia will organize joint sessions with symposia from other clusters establishing connections to methods for characterization and possible applications.

Soft Materials and Biomaterials: There are eight symposia in this broad interdisciplinary cluster. Key topics include fundamental and applied research in the following technical areas: advanced polymers, polymeric biomaterials, bioelectronics, materials for immunology, membranes, soft robotics, neural interfaces, multifunctional fibers, and biomineralization.

Symposium $\mathrm{X}$-Frontiers of Materials Research will feature lectures for the broad materials community on topics at the forefront of research on materials science and engineering. Julia Greer, California Institute of Technology,

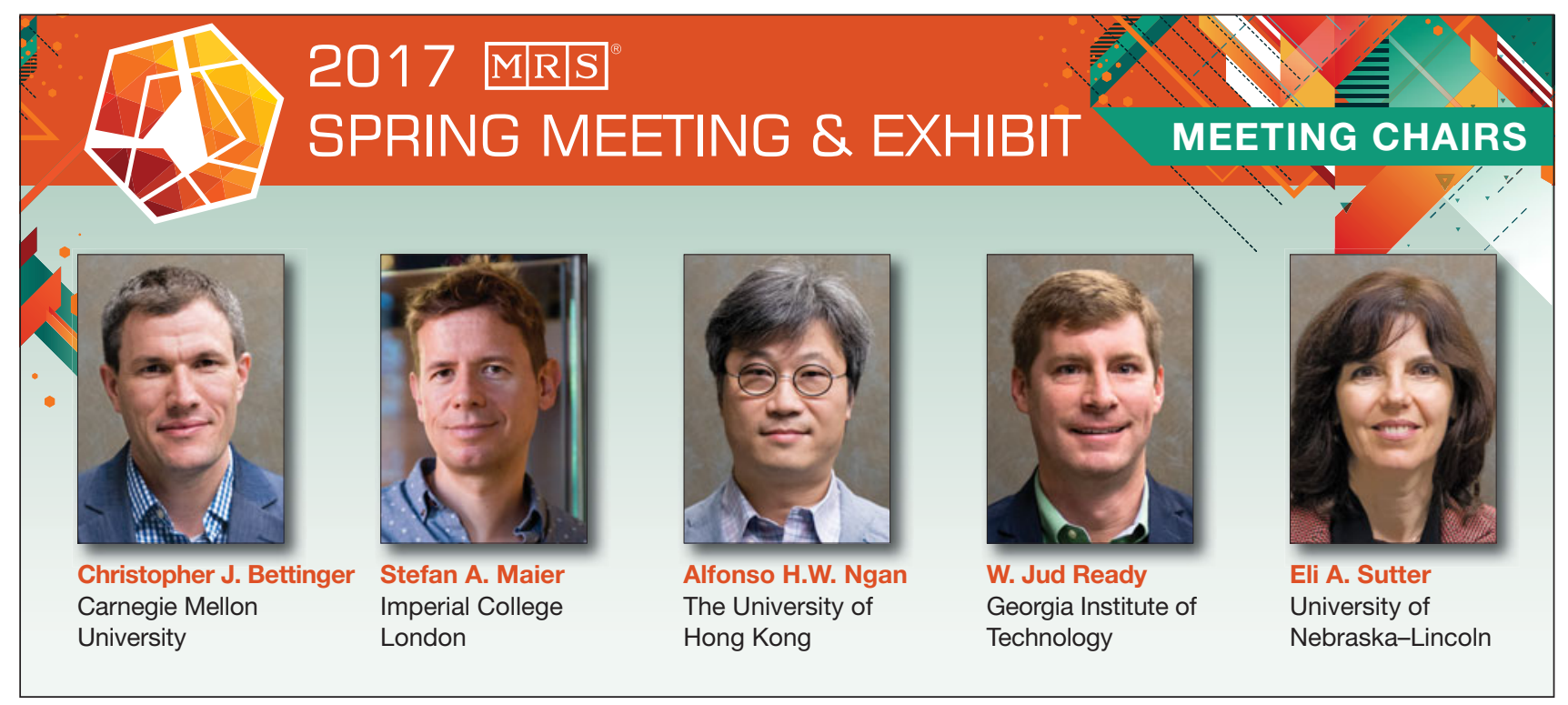




\begin{tabular}{|l|c|c|}
\hline 2017 MRS SPRING MEETING REGISTRATION RATES \\
\hline Meeting Registration & $\begin{array}{c}\text { PREREGISTRATION } \\
\text { before 5:00 pm (ET) } \\
\text { March 31, 2017 }\end{array}$ & $\begin{array}{c}\text { ON-SITE REGISTRATION } \\
\text { after 5:00 pm (ET) } \\
\text { March 31, 2017 }\end{array}$ \\
\hline Meeting Registration with MRS Member Discount & $\$ 655$ & $\$ 780$ \\
\hline Student Registration & $\$ 520$ & $\$ 645$ \\
\hline Student Registration with MRS Member Discount & $\$ 150$ & $\$ 180$ \\
\hline Unemployed & $\$ 115$ & $\$ 145$ \\
\hline Retired & $\$ 150$ & $\$ 180$ \\
\hline
\end{tabular}

2017 MRS Spring Meeting registrations include MRS membership through June 30, 2018.

will present a talk on Tuesday; David Weitz, Harvard University, will present a talk on Wednesday; and Kazu Suenaga, National Institute of Advanced Industrial Science and Technology, will present a talk on Thursday, all at 12:15 pm at the Phoenix Convention Center.

An award ceremony will be held to honor this year's Outstanding Young Investigators and MRS Fellows as well as the recipients of the Innovation in Materials Characterization Awardendowed by Toh-Ming Lu and GwoChing Wang - the Mid-Career Researcher
Award - endowed by MilliporeSigma, and the Gold and Silver Graduate Student Awards. The Meeting will also include a plenary address and a presentation by the recipient of The Fred Kavli Distinguished Lectureship in Materials Science, yet to be announced.

The Academic Affairs Committee is offering the ABET (Accreditation Board for Engineering) Information and Evaluator Retraining Session at the 2017 MRS Spring Meeting. Janet Callahan from Boise State University will be the instructor. This is an informational session and retraining for ABET evaluators and others interested in the accreditation process. You do not have to register for the Meeting to attend. The training will be held Tuesday evening (7:15-9:30 pm). Walk-ins are welcome.

If you are searching for an introductory-level undergraduate materials science course that will interest your students, stop by the Impact of Materials on Society Booth at the Public Outreach Center to view the new curriculum materials and engaging videos. MRS scientists and University of Florida faculty will be on hand to answer any questions.

Poster sessions will be held in the Sheraton, Third Level, Phoenix Ballroom, on Tuesday, Wednesday, and Thursday from 8:00 pm to 10:00 pm. The Meeting chairs will sponsor a Best Poster Award competition, selecting recipients each night on the basis of the posters' technical content, appearance, graphic excellence, and presentation quality.

The popular Science as Art competition will be held again at this Meeting. The competition is open to all registered Meeting attendees. Multiple first-place and second-place awards of $\$ 400$ and $\$ 200$, respectively, will be presented at

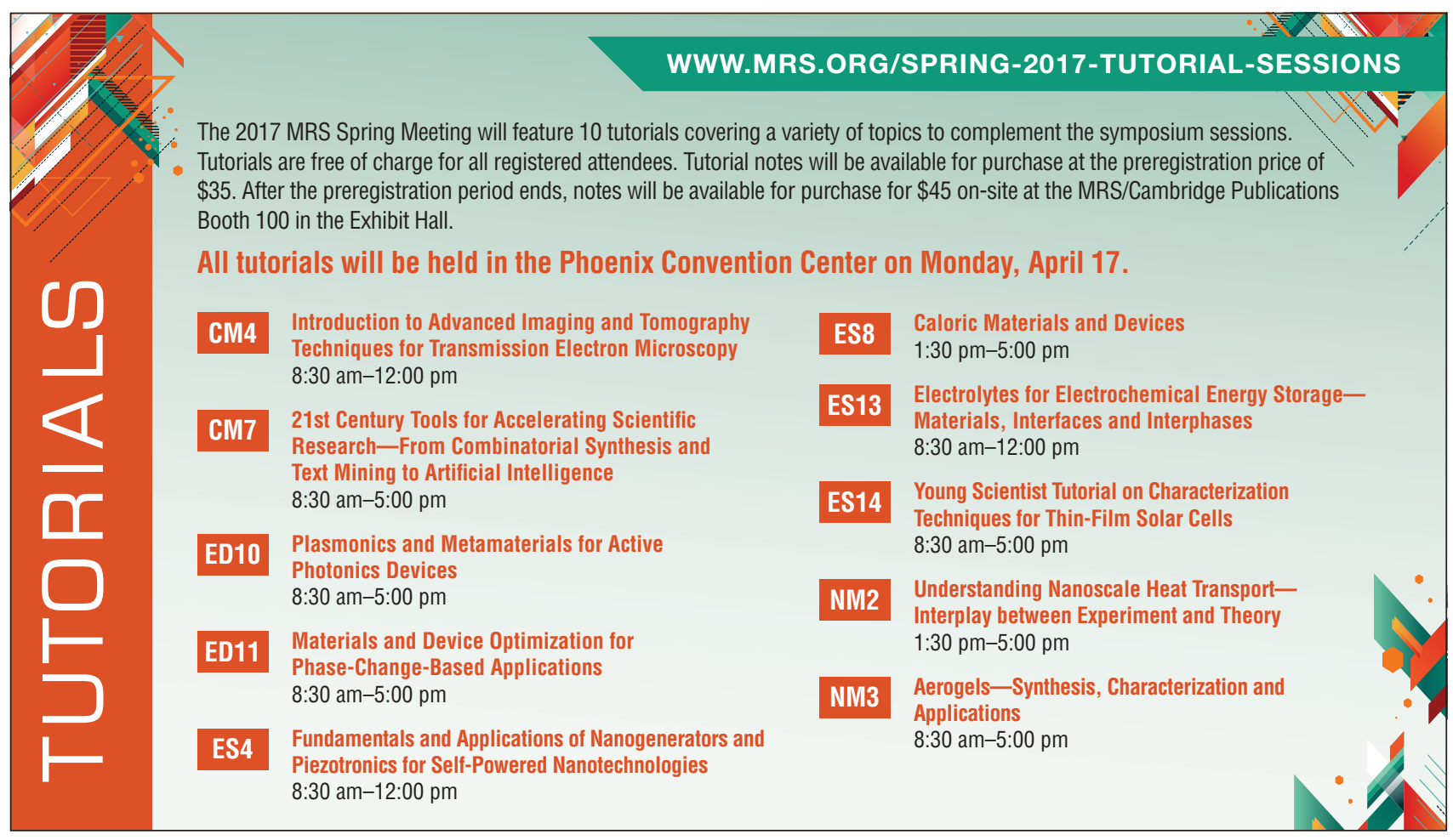


the Meeting. Guidelines and the deadline for entries will be available on the 2017 MRS Spring Meeting website.

MRS will host a Career Fair in the Exhibit Hall to connect job seekers with recruiters to discuss available career opportunities. Career-related professional development sessions will also be presented on the stage adjacent to the Career Fair to help job seekers navigate their job search.

Graduate students and members of MRS University Chapters are invited to attend the student mixer reception. Chapter officers and faculty advisors are also invited to attend a meeting of MRS University Chapter representatives to compare notes on recent activities and brainstorm new projects and issues of common concern. Those interested in starting new chapters are welcome.

Research Funding Opportunities includes presentations from US and nonUS agencies. Various events for professional development and public outreach are also planned.

The deadline to preregister for the MRS Spring Meeting is March 31, 2017 (5:00 pm ET). International travelers are reminded to begin the visa process early. For additional information on the Spring Meeting, contact MRS Member Services, email info@mrs.org; and tel. 724-779-3003.

The MRS website can be accessed for updated information on confirmed talks and details on special events, information on obtaining a visa, and preregistration at www.mrs.org/spring2017.

\section{HOTELS IN PHOENIX}

MRS receives meeting space at a greatly discounted rate as a result of contracting a large block of sleeping rooms at the official meeting hotels. In order to keep meeting costs as low as possible and minimize the financial risk to MRS, we encourage you to utilize official MRS housing while you are attending a MRS meeting. Hotels offering discounted rates for the 2017 MRS Spring Meeting are listed below. To make reservations, visit www.mrs.org/spring-2017-hotels.

Discounted room rates will be available until MARCH 12 or until the group block is sold out, whichever comes first.

- Sheraton Grand Phoenix

340 North 3rd St., Phoenix, AZ 85004 602-262-2500

Group Rate: \$159 single/double*

- Hyatt Regency Phoenix 122 North Second St., Phoenix, AZ 85004 602-252-1234

Group rate: $\$ 169$ single/double*

- Renaissance Phoenix Downtown Hotel 50 East Adams St., Phoenix, AZ 85004 602-333-0000

Group Rate: $\$ 167$ single/double*

- Palomar Phoenix

2 East Jefferson St., Phoenix, AZ 85004 602-253-6633

Group Rate: \$246 single/double*

- SpringHill Suites Phoenix Downtown 802 East Van Buren St., Phoenix, AZ 85006 602-307-9929

Group Rate: \$167 single/double*

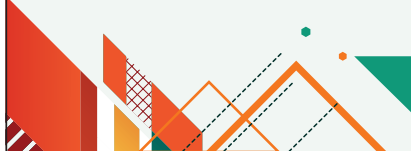

- Crowne Plaza Phoenix Airport 4300 East Washington St., Phoenix, AZ 85034 602-273-7778

Group Rate: \$159 single/double*

- Holiday Inn Express and Suites Downtown Ballpark

620 North 6th St., Phoenix, AZ 85004 602-452-2020 Group Rate: $\$ 189 *$

- Hilton Garden Inn 15 East Monroe St., Phoenix, AZ 85004 602-343-0006 Group Rate: \$199*

- Wyndham Garden Phoenix Midtown 3600 North 2nd Ave., Phoenix, AZ 85013 602-604-4900

Group Rate: $\$ 140^{*}$ King only with 2 person maximum; $\$ 150^{*}$ Queen only with 4 person maximum

* plus applicable taxes and fees

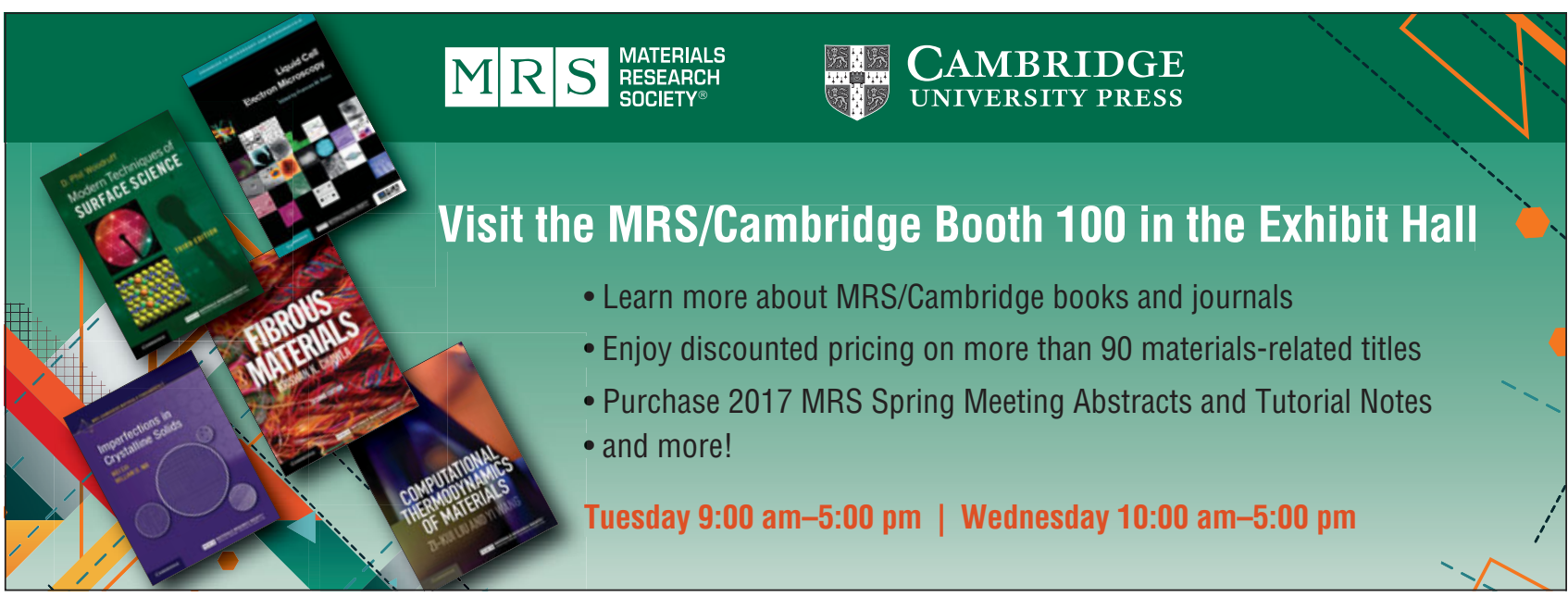




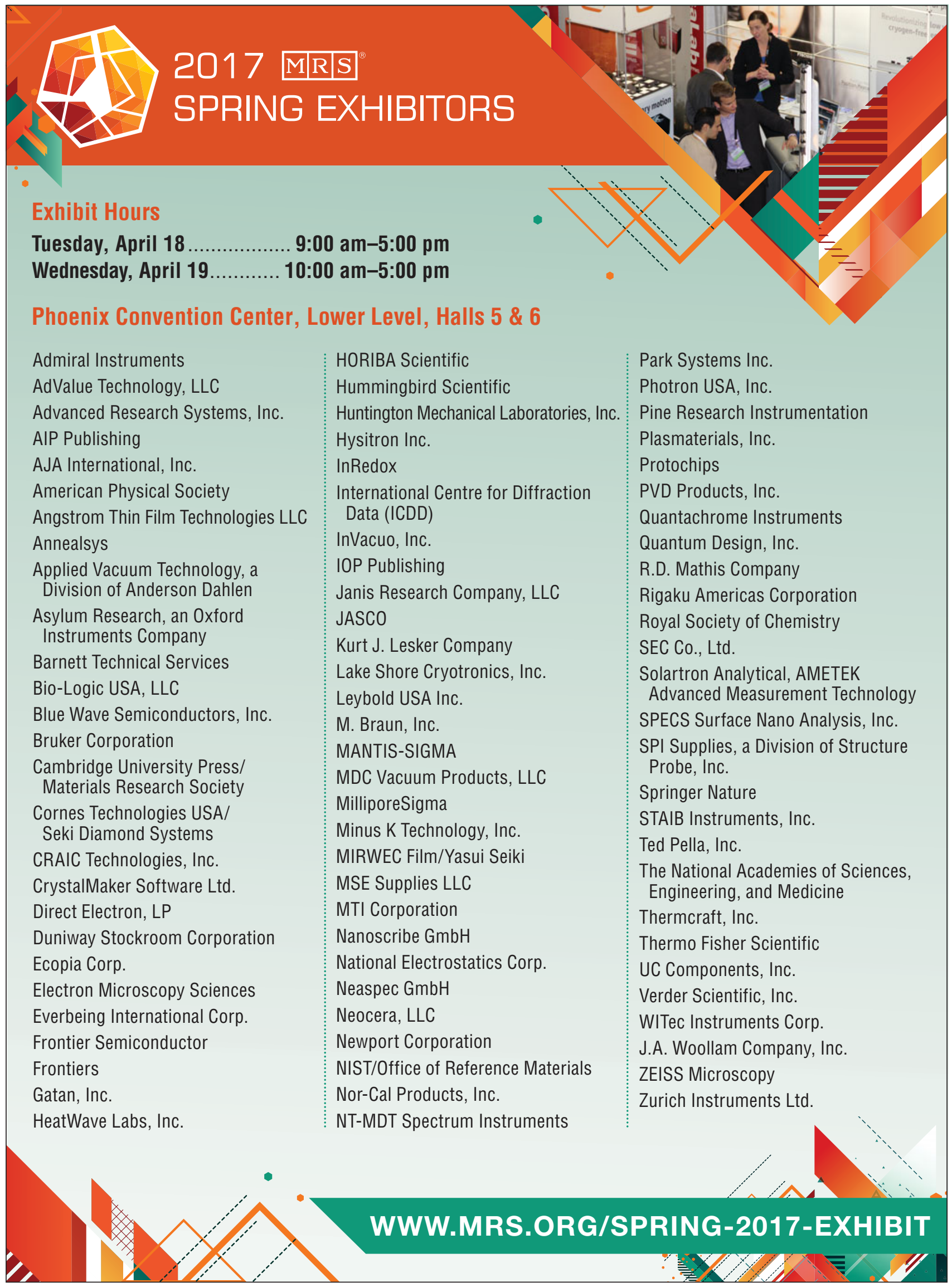

